\title{
AS TECNOLOGIAS INTERATIVAS NO ENSINO
}

Vítor F. Ferreira

Departamento de Química Orgânica - Instituto de Química - Universidade Federal Fluminense - Outeiro de S. João Batista s/n 24020-150 - Centro - Niterói - RJ

Recebido em 16/12/97; aceito em 12/3/98

\begin{abstract}
THE INTERACTIVE TECHNOLOGIES AND TEACHING. The way new interactive computer technologies and the resources of the Internet could be used by teachers and students are explored. The possibilities of some of the Internet resources in chemistry are described.
\end{abstract}

Keywords: Internet; teaching; technology; distance teaching; computer.

\section{INTRODUÇÃO}

Atualmente o mundo está se deparando com uma revolução nas comunicações entre os povos através das novas tecnologias de comunicação que estão disponíveis no mercado. Depois destas tecnologias terem alcançado vários setores da sociedade, a educação é uma das áreas que está sendo consideravelmente afetada por esta onda tecnológica. Basicamente estamos falando da introdução do computador nas salas de aulas, com seus programas interativos e acesso aos recursos da Internet. Uma pesquisa nas bases de dados do MEDLINE ${ }^{1}$ (dez/97) e Carl UnCover ${ }^{2}$ na palavra chave "Internet Education" indicou 565 e 190 citações, respectivamente, de trabalhos publicados nos últimos quatro anos.

Estas novas tecnologias têm causado desde uma grande euforia por alguns, até uma preocupação exagerada por outros educadores.

O objetivo deste trabalho é olhar as tendências atuais que estão ocorrendo nesta área, verificar as alternativas para os educadores e tentar observar como estas tecnologias estão se inserindo na área da química.

Neste aspecto identificamos, dentre várias outras, algumas questões que consideramos relevantes e que merecem uma reflexão: 1) Qual será a relação entre o professor e o aluno com esta onda tecnológica que está entrando no sistema educacional? 2) Como deverá ser a interação entre os alunos e estes recursos tecnológicos? 3) Qual o diagnóstico que pode ser feito atualmente nos países onde esta revolução tecnológica já está em andamento? 4) Para criar sistemas educacionais eficientes precisaremos de escolas com os mais sofisticados e atuais intrumentos tecnológicos? 5) Como a Internet está organizada para dar suporte ao professor e ao estudante? 6) O material que está sendo distruibuído na Internet é confiável? 7) O uso da tecnologia no ensino determinará o processo de aprendizagem, ou o processo de aprendizagem deverá determinar o uso da tecnologia no ensino? 8) Qual o tipo de impacto que se espera desta onda tecnológica no ensino? 9) Ela promove a melhoria do ensino? Ela aumenta o acesso a educação? 10) Como a química, uma ciência central, está participando deste processo? 11) Quais as áreas que atualmente têm mais se beneficiado com estas tecnologias?

\section{DISCUSSÃO}

Como mencionado anteriormente, as ferramentas tecnológicas estão se espalhando explosivamente na educação, principalmente na área da ciência. Porém, chegou-se a um ponto

email: cegvito@vm.uff.br onde os educadores devem dar um passo atrás e pensarem cuidadosamente como esta avalanche tecnológica se ajusta ao seu esquema educacional, pois existem muitos educadores que pensam que a tecnologia sozinha é uma panacéia para a educação e que, simplesmente aplicando toda esta tecnologia atual estarão resolvidos todos os problemas educacionais.

Alguns autores mostram que há uma tendência messiânica de colocar a tecnologia e o computador como salvadores da educação e dos estudantes, livrando-os das aulas chatas, dos pensamentos provincianos e da falta de motivação nas aulas tradicionais ${ }^{3}$. Tecnologia por si mesma não é uma cura radical e não vai resolver todos os problemas. Ela pode ser uma ferramenta para resolver alguns deles, mas sua aplicação pura e simples não solucionará a maioria destes problemas.

Nos parágrafos a seguir gostaria de discutir os vetores deste processo individualmente.

\section{O Professor}

"Books will soon be obsolete in the schools ......Scholars will soon be able to instruct through the eyes. It is possible to touch every branch of human knowledge with motion picture" . Thomas A Edison (1913).

Um dos elos mais importante neste processo são os professores, que precisarão decidir como irão atuar nesta revolução tecnológica. Pensar que a tecnologia, principalmente o computador e a Internet, substituirão os professores e que não devemos nos preocupar com a formação de novos professores, já é um sintoma de uma doença no processo ou um otimismo exagerado pelos mais iniciados nestas tecnologias.

Um dos problemas mais graves observados nesta onda tecnológica é a preparação adequada dos professores. Eles precisam ser motivados e encorajados ao uso da tecnologia no seu plano didático. Logo, novas formas de treinamento e atualização precisam ser cuidadosamente criadas visando dar opções de escolha aos educadores ${ }^{5}$. Além disso, para preparar e motivar os alunos para este novo ambiente tecnológico, os professores precisam estar equipados para ensinarem usando destas tecnologias. Neste caso é responsabilidade das "escolas-universidades" a provisão de tais ferramentas.

Alguns entusiastas do uso do computador na sala de aula chegam a afirmar que "os estudantes não ficam isolados com o uso do computador pois os professores estão lá para encorajálos (note-se não estão lá pra ensiná-los ou encorajá-los) e ao usarem o computador no ensino logo descobrem que as "máquinas" são suficientemente independentes e, no máximo o que eles poderão fazer é agir como treinador ou facilitador" ${ }^{\text {"6 }}$. Em nossa opinião utilizar computador imitando o professor é um erro de análise do contexto. 


\section{As Tecnologias}

"Technology is dominated by two types of people: those who understand what they do not manage, and those who manage what they do not understand". - Putt's Law

As culturas dos povos são continuamente moldadas pelo uso das tecnologias. A televisão, por exemplo, modificou o hábito das famílias e continua até hoje influenciando o comportamento da sociedade. No momento o mesmo fenômeno está acontecendo com a introdução das novas tecnologias interativas na sociedade ${ }^{8}$. Qualquer previsão, com precisão, de como ela vai se comportar frente a estas tecnologias, é especulação. Portanto, é de se esperar que o uso destas tais tecnologias interativas quando aplicadas ao processo de ensino-aprendizagem também cause mudanças de hábitos e comportamentos por parte dos professores e estudantes e, talvez, de políticos responsáveis pela política educacional do país.

Os termos tecnologias interativas aplicadas ao ensino ou ferramentas tecnológicas referem-se fundamentalmente aos meios instrucionais baseados nos recentes avanços computacionais interativos, como por exemplo: programas educacionais interativos, vídeo laser, CD-ROM, vídeo laser interativo, hipertexto, hipermídia, correio eletrônico (email), realidade virtual, programas simuladores e recursos da Internet (livros eletrônicos, periódicos eletrônicos, bibliotecas virtuais, listas de discussão, cursos a distância, educação continuada $)^{9 \mathrm{a}}$.

A questão do uso das novas tecnologias na escola não significa apenas um modismo, se as escolas e universidades pretendem formar cidadãos para se integrarem na sociedade. A utilização destes recursos ajuda a formar cidadãos e trabalhadores mais preparados funcionalmente ${ }^{9 b-f}$ (capital humano), pois em muitas áreas da sociedade estas tecnologias já estão a muito tempo em utilização (indústrias, comércio, transportes, bancos, etc.). Porém, o que se vê atualmente na maioria das escolas e universidades é o uso do giz e quadro negro. Apesar do quadro negro ter sido introduzido há mais de cem anos na sala de aula, ainda continua como o único recurso disponível para o professor. Talvez o quadro negro seja a tecnologia mais utilizada e difundida no mundo, até porque ainda continua tendo espaço útil, mesmo nas salas de aula equipadas com as mais avançadas ferramentas tecnológicas. Ele instiga a criatividade do professor e ainda hoje nos deparamos com cursos e seminários mostrando aos professores como utilizar mais eficientemente esta importante ferramenta para o ensino ${ }^{10}$.

\section{O Computador}

"There is no reason anyone would want a computer in their homes" - Ken Olson, Presidente e fundador da Digital Equipament Co. $(1977)^{11}$

As escolas podem utilizar mais efetivamente os recursos do computador para um melhor desempenho dos alunos. Alguns trabalhos demostraram que os programas interativos podem trazer melhorias consideráveis para o processo de ensino-aprendizagem, tanto nas aulas teóricas, quanto nas aulas experimentais $^{12 \mathrm{a}, \mathrm{b}}$. Os computadores se tornaram peças de destaque no mundo científico, nas áreas industriais, comerciais e outros setores da sociedade. Isto porque podem executar as tarefas pré-determinadas de forma muito mais eficiente e precisa que os seres humanos. Porém, o único campo em que o computador ainda não mostrou desempenho satisfatório foi na área educacional. Escolas têm gasto milhões (nos países desenvolvidos) em computadores com muito pouco progresso no ensino. Atualmente a maioria das salas de aula ainda são idênticas àquelas de vários anos atrás: livro, giz e quadro negro. Apesar da tecnologia do computador ter uma obsolescência rápida, talvez no futuro haverá um computador em cada sala de aula ou um "lap-top" para cada estudante ${ }^{9 b}$.

Novamente voltamos a enfatizar a importância central do professor neste processo de ensino mediado por computador. Esta ferramenta não é boa nem ruim na sala de aula. É o seu uso que vai determinar se ela contribuirá para um bom processo educacional ou não. Os alunos não são idênticos e diferem na inteligência, cultura, meio social e experiências anteriores. $\mathrm{O}$ mesmo estudante pode mudar de atitude de um dia para o outro dependendo da sua condição emocional. Será que os pacotes de aprendizagem disponíveis estão programados para lidar com estas situações? Só o professor no contacto pessoal é capaz de identificar, estimular a curiosidade e fazer um trabalho pessoal com o estudante, mesmo num ensino mediado por computador.

$\mathrm{O}$ dito ensino tradicional pode tornar-se muito mais eficiente e atraente quando se utiliza das tecnologias interativas. Como afirma Moretti - "o computador só funciona quando melhoramos o professor" $9 \mathrm{~b}$. Portanto, é ineficiente colocar computadores nas salas de aula sem trabalhar o professor e adequar o curriculum do curso para à uma nova proposta pedagógica.

Os pacotes de ensino-aprendizagem por computador devem ser robustos, confiáveis e de simples manipulação, para que esta tecnologia tenha seu lugar nesta sociedade em mudança rápida. Porém, estes pacotes devem ser colocados numa perspectiva em que pessoas (professores e estudantes) venham antes que as máquinas e os programas. A atitude de alunos e professores que utilizam computadores no ensino-aprendizagem devem ser constantemente avaliada.

O ensino tradicional vem apresentando um desempenho questionável $^{12 \mathrm{c}}$, assim como algumas experiências frustantes com o ensino mediado por computadores. Estas observações tem servido de ponto de partida para novas experiências ${ }^{12 \mathrm{~d}} \mathrm{e}$, muitos programas novos estão surgindo no mercado, principalmente voltados para um aprendizado mais individualizado por parte dos estudantes. Existem vários casos de sucesso relacionados ao uso do computador na escola recentemente relatados na literatura ${ }^{9 c}$, como por exemplo o ensino de idioma chinês, em que um programa bem projetado tem o potencial de melhorar significativamente o processo de aprendizagem, reduzindo os obstáculos para um entendimento mais profundo ${ }^{13}$. Um outro exemplo de sucesso em que o uso do computador vem apresentando um bom desempenho, é na área de ensino a estudantes com dificuldades de aprendizado devido a problemas físicos e mentais ${ }^{14}$. Porém, também existem casos onde o programa interativo é uma mera repetição dos procedimentos tradicionais. Há um trabalho recente na literatura que sugere o uso de um disco laser acoplado a um computador e uma leitora de códigos de barras. Nesta parafernália eletrônica o estudante pode ver o vídeo e responder perguntas, utilizando uma leitora eletrônica de códigos de barras. As perguntas aparecem na tela tendo como opção códigos de barras. A coisa toda mais parece com um exame de múltipla escolha acoplado a uma eletrônica avançada ${ }^{15}$.

\section{A INTERNET NA SALA DE AULA}

"Internet is so big, so powerful and pointless that for some people it is a complete substitute for life"- A. Brown ${ }^{16}$

A Internet é um sistema de computadores interligados e trocando informações através de um protocolo comum. Existe uma variedade de acessos à Internet diferenciados pelo serviço que oferecem e pelo protocolo de acesso (Telnet, FTP, WWW, Gopher, Email). Há uma estimativa de que existem 20 milhões de usuários espalhados no mundo e com um crescimento de um milhão por mês ${ }^{17}$.

Em alguns países a Internet já está instalada numa grande quantidade de residências, por exemplo: EUA (38,5 \%), Finlândia $(30 \%)$, Nova Zelândia $(>70 \%)$. Atualmente o acesso à Internet está indo para a sala de aula após se tornar popular nas residências. No final de 1996, 75\% das escolas nos EUA tiveram acesso à Internet mas apenas $14 \%$ estão em uma sala 
de aula ${ }^{18}$. Porém, apenas $5 \%$ dos professores a utilizou, apesar de que $20 \%$ dos professores tiveram treinamento no uso da Internet. Pelos dados coletados demonstra-se que o impacto na sala de aula ainda é muito limitado. Poucos professores fazem uso das informações contidas na rede por falta de conhecimento em telecomunicações ${ }^{19}$. Recentemente foi feita uma pesquisa sobre como os professores estão utilizando os recursos da Internet, como foram treinados e como as informações são obtidas. Os resultados não foram muitos conclusivos, mas indicaram que o uso efetivo de apoio da Internet no ensino de ciências começou efetivamente em 1990 e que a maioria dos professores aprenderam a manipular a rede por si só. Poucos tiveram o incentivo das escolas para participarem de programas de treinamento ${ }^{19 a, b}$.

Inicialmente toda inovação tecnológica na educação é recebida com enorme entusiamo. Porém, após algum tempo para uma análise mais detalhada, a realidade destas tecnologias aparecem. No caso da Internet, aqueles mais conhecedores dos meandros da rede, sabem que a mesma se tornou um grande "karaokê", pois as informações não são tão fáceis de serem coletadas, como acreditam alguns. Do jeito que a rede está estruturada as experiências, nas salas de aulas, foram frustantes e desapontadoras para os professores ${ }^{20,21}$.

A Internet é uma excitante ferramenta para a sala de aula. Ela expande consideravelmente a sala de aula através de troca de informações, dados, imagens e programas de computadores, chegando a lugares muito distantes quase que instantaneamente. Fundamentalmente a Internet é um lugar para comunicação, conseguir informações, ensinar e aprender ${ }^{22}$. O uso da Internet no ensino tira o caráter de conhecedor-único do professor, conduzindo a um novo modelo no qual a responsabilidade pelo aprendizado passa pela busca individual do estudante. Para isso a escola tem que estar estruturada e o professor preparado para este novo tipo de interação com o estudante. A Internet pode ter um papel fundamental neste ambiente de troca. Assim como livros, visitas técnicas, pesquisa de campo, periódicos, vídeos, e seminários dão suporte a formação do estudante, a Internet também pode ser utilizada no processo de ensino-aprendizagem. Neste processo, os professores continuarão a ser os responsáveis em avaliar e decidir como a Internet poderá ser utilizada como ferramenta na sua aula.

Existe espaço na escola para todo o tipo de ferramenta educacional cujo objetivo seja prover o melhor aprendizado para o estudante. Sem dúvida nenhuma, livros e outros materiais impressos continuarão sendo importantes na escola. A Internet apenas expande os horizontes a muito além da biblioteca e de uma forma mais atualizada, principalmente nas escolas onde não existem bibliotecas (muito comum) ou ela é muito defasada da atualidade.

Um fator que desabona o uso do material obtido na Internet é a confiabilidade, pois muitos não passaram por um processo de avaliação por pares como acontece com os artigos dos periódicos ${ }^{22 \mathrm{a}-\mathrm{c}}$. A "Rice University" oferece no seu servidor recomendações básicas para quem faz pesquisa na Internet ${ }^{22 c}$. Neste aspecto pode-se traçar um paralelo entre as páginas de ciências do jornal O Globo ${ }^{23}$ e NetSci (ISSN 1092-7360) ${ }^{24}$, onde os artigos publicados são explicitamente de pura responsabilidade dos autores, enquanto que no "Journal of Chemical Education on line" o material publicado passa por árbitros e sua qualidade é referendada pela "American Chemical Society". Apesar de acharmos relevante o serviço que estes sítios estão prestando à educação e à pesquisa, cabe exclusivamente aos professores, que estão utilizando o material disponibilizado fazerem sua própria avaliação antes de utilizá-lo como material didático na sua sala de aula. Por outro lado, cabe recordar que muitos dos livros didáticos publicados também não passam por um processo de avaliação rigorosa pelas editoras, e o que se tem visto nas avaliações promovidas pelo MEC são livros publicados contendo conceitos errados, pensamentos racistas e sem nenhuma consistência didática. Portanto, a grande parte do material colocado no mercado pelas editoras não tem credenciais confiáveis e da mesma forma cabe ao professor avaliar sua adequabilidade para sua classe.

Sem dúvida nenhuma, a Internet é uma oportunidade de ouro para a pesquisa e o ensino. Porém, uma avaliação crítica do uso potencial desta fonte de recursos educacionais para as escolas média e superior, principalmente no que diz respeito a quantidade e a confiabilidade destas informações, precisa ser feita. Recentemente vários grupos de usuários vem tentando coletar e organizar estas informações para que sejam melhor aproveitadas pelas escolas. É desejável que qualquer cidadão com uma dúvida que necessita de uma resposta rápida possa explorar a Internet de forma eficiente. Somente assim ela se tornará uma fonte valiosa e ilimitada de informações.

Recentemente foi publicado um trabalho interessante que mostra que uma nova parceria pode emergir entre os cientistas e educação. Esta parceria estaria baseada na possibilidade dos estudantes poderem participar ativamente nas pesquisas desenvolvidas pelos cientistas via Internet ${ }^{25}$. Desta forma os pesquisadores mais preocupados com o processo educacional poderão contribuir para a melhoria do ensino de ciências (nível médio ou superior) substituindo a forma antiga e esporádica de visitas e seminários nas escolas. Esta interação a que se refere o autor do trabalho pode ser do tipo observações, monitoramento e análise de dados coletados pelo grupo de pesquisas (estudos do meio ambiente, biodiversidade, doenças na comunidade, pesquisas meteorológicas, microbiologia, etc). Basicamente, existem três tipos de parceria: 1) o cientista define o programa de pesquisa e o protocolo, e os estudantes analisam os dados coletados, 2) o cientista define e dá suporte ao tópico para a pesquisa, porém o estudante conduz o estudo e 3) o estudante conduz e estabelece os protocolos da pesquisa enquanto o pesquisador funciona apenas como consultor, orientador e revisor do trabalho.

A Internet tem causado a preocupação não só do ponto de vista educacional, como também do ponto de vista das relações pessoais. Alguns autores têm levantado questões relacionadas aos usuários mais constantes da Internet ${ }^{26}$. Algumas pessoas são tão viciadas com o uso que se arruinaram na escola, perderam seus casamentos, empregos e diminuiram sensivelmente sua relação pessoal com outros companheiros. Outras se tornaram psicologicamente estressadas, doentes e de difícil relacionamento após longo uso da Internet. Estas pessoas pensam que suas "máquinas" são o próprio Deus e que você não é benvindo a não ser que também seja um adepto do uso da Internet. Estas preocupações parecem em princípio um tanto descabidas, e parece haver uma contradição ${ }^{21}$. Enquanto, a Internet reduz as barreiras do mundo, nos leva a lugares muito distantes e nos coloca em contato com pessoas das mais variadas culturas, ela reduz o contato com outros seres humanos mais próximos se for usada por longo período de tempo.

Outros aspectos, como direito autorais ("copyright") das publicações eletrônicas, plágio e citações bibliográficas, têm sido discutidos recentemente $22 c, 27 a$. Além destas, outras questões, sobre a distribuição de material ilegal e de intenções questionáveis têm sido alvo de preocupações ${ }^{27 b}$. Alguns trabalhos estão sendo desenvolvidos no sentido de classificar os sítios da rede, como por exemplo o PICS Standard ${ }^{28}$ e o NetShepherd Rating ${ }^{29}$, de uma forma similar como já é feito para os filmes e vídeos ${ }^{30}$.

\section{PROJETOS COLABORATIVOS VIA INTERNET}

$\mathrm{Na}$ área educacional a Internet está revolucionando principalmente o estudo de ciências (química, física e biologia), pois os alunos não precisam estar no mesmo lugar do seu laboratório, seu professor e de seus colegas. Dados podem ser obtidos e os professores podem dar orientação a distância ${ }^{31}$. Muitos 
tipos de projetos colaborativos estão disponíveis na Internet ${ }^{32}$. Estes projetos podem servir para o planejamento, orientação aos estudantes e para traçar os curricula de cursos ou de uma escola. Estes projetos são normalmente voltados aos ensinos primário e secundário. Estão agrupados em alguns sítios e oferecem a oportunidade de se conhecer os que estão em andamento ou adotar seu próprio projeto. São excelentes as oportunidades para os professores e alunos conhecerem os trabalhos que outros grupos de estudantes estão desenvolvendo. Podemos citar alguns exemplos: Global Schoolnet Foundation $^{33}$, International Education and Resources ${ }^{34}$, Teacher web site ${ }^{35}$ e NASA ${ }^{36}$.

\section{ENSINO A DISTÂNCIA E EDUCAÇÃO CONTINUADA}

A idéia de ensino a distância e educação continuada não é nova. Muito antes dos computadores e a Internet se tornarem populares, já existiam os cursos por correspondência. Porém, a introdução destas novas tecnologias interativas deram a estes cursos uma dimensão muito maior em termos de número de alunos e área territorial, além de uma dinâmica quase que em tempo real. Num curso tradicional o professor precisa estar no mesmo lugar e na mesma hora que o estudante. Isso não acontece com cursos ministrados via correio eletrônico ("email") ou pela Internet. Via correio eletrônico o programa e as aulas semanais são distribuídas aos estudantes, que precisam ler o material e responder as questões também via correio eletrônico, pelo menos uma vez por semana ${ }^{37}$. Já os cursos de aprendizado a distância via Internet são mais dinâmicos pois podem utilizar hipertextos, recursos de multimídia e programas interativos. Ambos os veículos oferecem a oportunidade dos estudantes formarem um grupo de discussão com o professor e a classe. Um trabalho interessante desenvolvido na UFRGS sob o título "Fatores Determinantes na Efetividade de Ferramentas de Comunicação Mediada por Computador no Ensino a Distância"38 está disponível na Internet e aborda com mais detalhes as implicações das ferramentas de comunicação no ensino e educação a distância.

Nos cursos tradicionais, a biblioteca é um ponto de apoio fundamental. Nos cursos a distância a Internet se torna a biblioteca mais adequada, pois além da pesquisa que pode ser mediada pelos serviços de busca (Yahoo, Lycos, Webcrawler, infoseek, Alta Vista, Search.com, Servy Search, Open Text), pode-se também consultar diversas bibliotecas virtuais ${ }^{39-41}$.

Alguns problemas podem ser identificados neste tipo de ensino, como por exemplo: 1) os alunos precisam ter acesso fácil à Internet, 2) alguns valores como a interação pessoal com o professor são perdidos, 3) a Internet é um veículo muito dispersivo e 4) o material não é muito bem assimilado. Entretanto, o mesmo é sempre dito a respeito das aulas tradicionais onde, os estudantes também não assimilam a totalidade do material apresentado pelo professor. Daí vem a preocupação de como a Internet poderia criar um ambiente para um aprendizado efetivo e como poderia oferecer um sistema de comunicação que acelere o processo de aprendizagem. O uso do correio eletrônico entre professor e classe e entre os membros da classe pode ajudar os estudantes a superar o problema do isolamento e falta do contato com o professor.

A educação a distância e a educação continuada vêm se beneficiando consideravelmente dos materiais publicados na Internet. Porém, para que a rede seja efetivamente utilizada como ferramenta para o ensino a distância, é preciso que esta quantidade enorme de material seja bem estruturada, pois senão estas informações serão inúteis tanto para o professor como para o estudante ${ }^{42}$. Felizmente neste aspecto esta é a área que está mais estruturada na rede. Existem dezenas de escolas e centros especializados oferecendo continuamente cursos a distância, como por exemplo o "Distance Learning Resources for Distance Educators" $"$.

$\mathrm{Na}$ área de educação continuada as sociedades científicas têm desempenhado papel fundamental, publicando diversas informações para o aprimoramento dos profissionais. Além disso, os pesquisadores e profissionais continuam colocando artigos, arquivos e livros nas suas "home pages" pessoais. Estes materiais devem interessar às pessoas que buscam aperfeiçoamento profissional a distância ${ }^{44}$. A maioria das referências obtidas para a elaboração deste trabalho foram obtidas na própria Internet.

De forma nenhuma os cursos eletrônicos vão substituir a sala de aula tradicional, assim como os cursos por correspondência não o fizeram. Mas são muito importantes para aqueles que por algum motivo estão impedidos de estar numa sala de aula. É importante lembrar que os cursos a distância não promoverão a mesma experiência pessoal que um curso tradicional, porém, espera-se que estes levem ao estudante o mesmo conhecimento teórico oferecido pelos cursos tradicionais, colocando os alunos de ambos os cursos no mesmo nível de conhecimento $^{45}$. Portanto, esta poderosa opção para proporcionar informação e educação a distância não deve ser desconsiderada, principalmente na área da educação superior, onde o processo de educação continuada é muito relevante.

\section{PROGRAMAS INSTRUCIONAIS EM QUÍMICA}

A química apesar de ser uma ciência eminentemente experimental, também tem um lado muito visual. Muitas das teorias utilizadas para explicar as reações químicas e a reatividade das substâncias na escala sub-atômica necessitam de um modelo, como por exemplo, orbitais atômicos, orbitais moleculares, ressonância magnética nuclear, espectroscopia eletrônica, etc.

O conceito de aprendizado mediado por computador não é novo ${ }^{46}$. Neste aspecto os programas interativos e os programas simuladores voltados a aperfeiçoar o processo de ensino-aprendizagem podem ajudar os alunos a transformar o modelo em seu próprio senso comum. Um grande número destes aplicativos estão no mercado para venda e muitos outros exemplos têm sido descritos recentemente na literatura. Por exemplo, o uso de um programa simulador de densidade eletrônica mostrou que este conceito, ao ser introduzido na aula teórica, foi muito melhor compreendido pelos estudantes ${ }^{47}$.

Saber como o estudante relaciona seus conhecimentos prévios com o material didático que está sendo apresentado é um dos mais importantes fatores no desenvolvimento do tema que está sendo estudado (mudança conceitual). Nos cursos experimentais de química os experimentos são precedidos de uma mini-aula com a intenção de mostrar ao estudante como tal experimento se relaciona com as teorias da química. Neste aspecto foi demonstrado, por pesquisa de opinião, que o uso de vídeo disco laser precedendo as aulas experimentais tornam-nas mais agradáveis e melhorou o entendimento até dos assuntos mais difícies de serem assimilados pelos estudantes, como por exemplo o conceito de oxidação-redução ${ }^{48,49}$.

Para ter um impacto na aprendizagem, estes programas ou CD-ROMs devem ser completos, representando uma parte significativa de uma determinada disciplina. Porém, o que se observa é que estes programas educacionais tendem a ser uma coletânea de programas fragmentados em tópicos isolados e muitas das vezes sem conexão entre $\mathrm{si}^{50}$. Por exemplo, o "Journal of Chemical Education" tem para venda uma coleção de programas e CD-ROMs destinados exclusivamente ao aprendizado individual do estudante fora da sala de aula. Como estes programas não são destinados aos cursos e sim ao estudante, a fragmentação parece ser uma questão mercadológica. Um trabalho interessante foi desenvolvido pela Universidade de Illinois que desenvolveu uma rede integrada de programas instrucionais em química, visando evitar o processo de fragmentação ${ }^{51}$.

Informações sobre os programas interativos mais atuais e os seus custos na área de química podem ser obtidos na "Chemistry Software and Information Resources"52. A Netlib" 
um serviço mantido pela Universidade do Tenessee, oferece a oportunidade de se conseguir muitos programas instrucionais grátis, assim como outros serviços ${ }^{54}$. Outros programas como o Chemland ${ }^{55}$, programa para a simulação interativa em reações química e o RasMol ${ }^{56}$, destinado para observação de estruturas complexas (DNA, proteínas, Heme, etc) estão disponíveis gratuitamente na Internet.

\section{QUÍMICA NA INTERNET}

A populariedade da Internet entre os químicos pode ser comprovada pelo grande número de sítios individuais, comerciais, bases de dados de substâncias químicas, conferências eletrônicas ${ }^{57-62}$, programas interativos ${ }^{63}$, listas de discussão, grupos de usuários ${ }^{64}$ e periódicos/revistas eletrônicos ${ }^{65}$ relacionados com assuntos da química. Isto demonstra claramente que a química já está bem disseminada na Internet, podendo dar suporte ao estudante e ao professor ${ }^{66-68}$. Este suporte pode se dar na forma de artigos em jornais (alguns gratuitos), livros eletrônicos e cursos, além dos serviços citados anteriormente.

A busca por esta enorme quantidade de informações pode ser tediosa e consumir tempo precioso na Internet ${ }^{69}$. Uma questão que se levanta é que tipo de informação é útil para o estudante e para o professor? O que se pode encontrar gratuitamente na rede? Nos parágrafos abaixo, tentaremos dar algumas respostas e informações na área de química que poderão ser úteis ${ }^{70-73}$.

As listas de discussão ("mailing list") são grupos de pessoas que trocam informações sobre um determinado assunto específico via email. Existem milhares destas listas de discussão com uma enorme quantidade de material interessante, porém muitas não tem índice que dê acesso às informações discutidas. A fim de organizar as informações sobre química, a base de dados AskNPAC ${ }^{74}$ dá acesso a milhares de mensagens que foram enviadas e discutidas nos grupos de usuários em química (usenet). $\mathrm{O}$ diretório Liszt ${ }^{75}$ catalogou até o momento cerca de 66.000 destas listas. Este catálogo dá informações e endereços sobre estas listas de discussão. Só na área de química existem 198 listas catalogadas. O acesso às informações das listas é grátis e pode-se obter respostas rápidas às mais variadas questões. Portanto, são de grande utilidade pública.

Em termos de base de dados ou sítios de interesse em química que podem ser acessados gratuitamente podemos citar: MEDLINE $^{1}$, Carl UnCover ${ }^{2}$, ChemFind ${ }^{76}$ (informações sobre iv, rmn, constantes físicas, toxicidade, etc), Fact $^{77}$ (um catálogo de espectros de massas), QPAT.US ${ }^{78}$ (acesso gratuito aos resumos das patentes emitidas nos EUA desde 1974, Patent-Server-IBM ${ }^{79}$ (busca gratuita de patentes americanas (completas) desde 1971), Beilstein NetFire ${ }^{80}$ (busca na base de dados Beilstein com gratuidade temporária); NIST Chemistry WebBook ${ }^{81,82}$ (permite a busca de dados espectroscópicos, físicos-químicos e constantes de substância por nome, fórmula, fórmula parcial e peso molecular), ChemDex ${ }^{83}$ (um diretório das universidades e sociedades científicas relacionadas com a química), WebElements ${ }^{84}$ (várias versões da tabela periódica e informações individualizadas de todos os elementos), Chemist's Art Gallery ${ }^{85}$ (exemplos de visualizações de reações químicas e substâncias produzidas por vários grupos no mundo); Educational Materials for Organic Chemistry $^{86}$, Chemistry Resources in the Internet ${ }^{87}$, ChemCal ${ }^{88}$ (programas e informações em geral na área de química), WWW no Ensino de Química Inorgânica ${ }^{89}$, Simulations ${ }^{90}$ (simulações de algumas das reações mais comuns), Chemistry Web Internet Resources $^{91}$, Experimental Chemistry ${ }^{92}$ (curso experimental de química orgânica), InfoChem ${ }^{93}$ (informações sobre conferências com especial enfase nos periódicos e sítios europeus), Conference Listing ${ }^{94}$ (listas das principais conferências e congressos acontecendo no mundo da química), Laboratório Aberto IQ-USP $^{95}$ (projeto do GEPEC IQ-USP com experimentos e bibliografia destinados ao apoio de professores do $1^{\circ}$ e $2^{\circ}$ graus), A Química na Internet ${ }^{96}$ (vários sítios da WWW relacionados à
Química que foram selecionandos por Max Kopelevich, ligados ao sítio da SBQ, contendo uma lista completa dos endereços das universidade que tem departamentos de química), ChemTean (trabalhos clássicos da química com album de fotos dos químicos mais conhecidos ${ }^{97}$, curso introdutório de estereoquímica $^{98}$ (em português e com excelentes imagens interativas de susbtâncias quirais), The Othmer Library ${ }^{99}$ (biblioteca dedicada a história da química), Nobel prize Archive in Chemistry ${ }^{100}$, Institute for Learning Technologies ${ }^{101}$ (dedicado ao estudo da função dos computadores e as tecnologias da informação na educação e sociedade), Chemistry Teaching Resource $^{102}$ (excelente sítio com as conexões mais variadas e interessantes em química), Educational Materials for Organic Chemistry ${ }^{103}$ (livro interativo de química orgânica com um mapa das reações químicas que muito ajuda a entender a química orgânica de forma integrada), The Organometallic Hypertext Book ${ }^{104}$, livro sobre introdução à quimiometria ${ }^{105}$, livro sobre problemas em reações pericíclicas ${ }^{106}$, livro sobre cromatografia líquida ${ }^{107}$ e Polymer Chemistry Hypertex ${ }^{108}$.

Como pode ser visto nos parágrafos anteriores, apesar de existirem muitas informações sobre química disponíveis na Internet, elas ainda estão muito fragmentadas e desorganizadas $^{109}$. Seria possível existir um sítio com todas as informações e "links" em química necessárias aos estudantes, alunos e cientistas? Um lugar que servisse de ponto de referência? Devido à quantidade de informações, isto seria quase que impossível. Porém, recentemente (abril/97) foi lançado um clube de assinantes chamado de ChemWeb ${ }^{\text {tm,110 }}$ que pretende integrar comércio, aplicações, bancos de dados e pesquisas com informações primárias de periódicos. Os assinantes além de ter informações, também podem publicar seus artigos e trocar informações com outros assinantes. Algo similar aos clubes de assinantes "Chemistry Place" (um dos sítios mais visitados na Internet, que possui cerca de 100.000 assinantes) $)^{113 .}$

\section{CONCLUSÕES}

"O computador pode fazer muitas coisas - inclusive derrotar o maior campeão de xadrez do mundo, como fez o Deep Blue com Boris Kasparov. Mas não existe o menor sinal que algum dia, venha a se apaixonar". Gilberto Dimenstein ${ }^{9 c}$

Neste trabalho procuramos dar uma visão geral sobre os usos das novas tecnologias interativas no ensino, procurando não advogar nem a favor nem contra o uso destas ferramentas, mas procurando mostrar os pontos positivos e negativos de seu uso ${ }^{114}$. É a política educacional do país, a pressão sobre os professores e o crescente acesso a estas tecnologias interativas que definirão os novos paradigmas para o processo de ensino-aprendizado.

Os mais recentes trabalhos publicados, em papel e/ou via eletrônica, mostraram que fundamentalmente informação não é conhecimento, ou seja, acesso a informação não produz um estudante bem educado.

De uma forma geral, apesar de existirem provas que a tecnologia pode contribuir significativamente para o ensino, poucos professores fazem uso destes recursos.

Mostrou-se que a Internet é a grande estrela do momento e que terá uma enorme influência nas áreas social, cultural e educacional, pois de uma forma geral diminui as barreiras de criação e distribuição de material.

A comunidade de pesquisa continua ainda sendo a principal interessada na rede, apesar da desorganização das informações e da invasão pelas áreas comerciais. Porém, na realidade é a fonte mais excitante que pesquisadores, professores e estudantes têm atualmente a sua disposição.

Existem dois tipos de informações na Internet que podem ser utilizadas no processo de ensino-aprendizagem: uma é o que já está disponível na Internet e a segunda é o que você 
pode publicar na rede através de uma "home page" individual. O resultado pode ser muito gratificante para o aluno e para o professor ao ver que seu trabalho está sendo lido, criticado e usado por outros.

Só o uso das tecnologias como ferramentas não será suficiente para dar boa continuidade ao processo de ensino-aprendizagem. Alguns fatos devem ser mencionados como por exemplo, a atitude positiva dos professores frente a estas tecnologias. A organização das aulas em torno da Internet e outros produtos tecnológicos é recomendável. Contudo, a determinação clara dos objetivos do ensino por parte dos professores é um dos pontos mais significativos do processo.

Em resumo final, o mais importante no uso das tecnologias interativas e da Internet no ensino é a abordagem pedagógica que o professor pode imprimir e não a tecnologia em si.

\section{AGRADECIMENTOS}

À CAPES pela apoio financeiro.

\section{REFERÊNCIAS E NOTAS}

1. Base de dados Medline, http://www.ncbi.nlm.nih.gov/pubmed

2. Base dados Carl UnCover Co., http://uncweb.carl.org

3. Mosbacker, B. L. Educ. Digest 1996, 61, 40.

4. Mourssund, D.; "The Future of Information Technology in Education"; ISTE, Oregon, USA, 1997. Esta referência pode ser obtida no endereço: http://www.iste.org

5. Dori, Y. J.; Barnea, N. Int. J. Sci. Educ. 1997, 19, 577.

6. Bennett, F.; "Computer as a Tutor: Solving the Crisis in Education"; 1997. Este documento pode ser obtido no endereço: http://www.cris.com/ faben1

7. Putt'S Law, http://www.starlingtech.com/quotes/qsearch.cgi

8. Madan, N.; "The Internet and Its Effects on Contemporary Culture and Society"; dissertação, The University of Birmingham, 1996, 23p. http://www.cb1.com/cb1/ nikki-madan).

9. a) Kimmel, H.; Deek, F. J. Sci. Educ. Tech. 1996, 5, 111; b) Dimenstein, G., "Computadores Redefinindo o Novo Analfabeto", 1997, http://www.colband.com.br/cidadao/tribuna/ftoque.htm;

c) Dimenstein, G., "Como as Novas Tecnologias viraram a Educação de Pernas para o Ar", 1997, http:// www.colband.com.br/cidadao/tribuna/ftoque.htm;

d) Dimenstein, G., "O Aprendiz do futuro (complementar)"; Ed. Ática, S.P, 1997, http://www.aprendiz.com/aprendiz;

e) Gilster, P. Business Leader 1995, 7, (5), nov., http:// www.businessleader.com/blnov95/gilster4.html;

f) McClintock, R., Power and Pedagogy: Transforming Education through Information Technology", 1992, NY, Institute for Learning Technologies, http://www.ilt.columbia.edu/ academic/texts/mcclintock/pp/title.html

10. Krauss, J.; "Taming the Blackboard Jungle"; 1997, http:/ /www.register.com/blackboard/contents.htm

11. Oslon, K.; Quotation Page; http://www.starlingtech.com/ quotes/qsearch.cgi

12. a) Gladwin, R. P.; Margerison, D.; Walker, S. M. Computer Educ. 1992, 19, 17;

b) Watson, J. G., "Educational Technology: A Necessity for the $21^{\text {st }}$ Century - Why the Delay", 1996. http:// www.edexcellence.net/library/watson.html;

c) Heidmann, W.; Waldman, W. D.; Moretti, F. A., "Using Multimedia in the Classroom"; 1996, The Dalton School, http://www.dalton.org/faculty/wolfgang/pages/ ICTEMultimedia.html;

d) McClintock, R.; Chou, L.; Moretti , F. A.; Nix, D. H., "Technology and Education: New Wine in New Bottles Choosing Pasts and Imagining Educational Futures", 1993,
New York, Institute for Learning Technologies, http:// www.ilt.columbia.edu/ilt/papers/newwine1.html

13. Bolduc, L.; J. Sci. Educ. Technol. 1997, 6, 91.

14. Kumar, D.; Wilson, C. L. J. Sci. Technol. 1997, 6, 155

14. Barnes, D.; Walter, R. British J. Spec. Educ. 1997, 24, 27.

15. Clark, D. R.; Rest, A. J. Educ. Chem. 1996, 5, 79.

16. Brown, A.; Quotation Page; http://www.starlingtech.com/ quotes/qsearch.cgi

17. Roblyer, M. D. Learning Leading Technol. 1997, 25, 54; Zimman, B. Comm. Jornalism Educ. Today 1996, 29, 5; Scneider, D.; Block, K.; "The World-Wide Web in Education"; 1995. http://tecfa.unige.ch/tecfa/research/cmc andreas/ andreas.txt

18. Heaviside, S.; Riggins, T.; Farris, E.; "Advanced Telecommunication in U. S. Public Elementary and Secondary Schools"; National Center for Education Statistics, fev. 1997. Este trabalho pode ser obtido no endereço: http:// nces.ed.gov/pubs/97944.pdf

19. a) Owston, R. Educat. Res. 1997, 27, 27;

b) Landis, C.; Murphy, T.; Schretter, T.; Haury, D. L.; J. Sci. Educ. Technol. 1995, 4, 181.

20. Jackson, D. F.; Bourdeau, G.; Sampson, A.; Hagen, T. J.; J. Sci. Educ. Technol. 1997, 6, 49.

21. Mosbacker, B. L. Educ. Digest 1996, 61, 40.

22. a) Robichaux, J.; Seller, J.; "Question About the Internet in an Education Setting"; Network Working Group, 1996. ftp://ds.internic/rfc/941.txt; b) Green, D. W. Fron Now On: The Educational Technol. J. 1997, 6 (4), jan., http:/ /fromnowon.org/jan97/websearch.hmtl; c) Rice University, $\mathrm{http} / /$ rice.edu/fondren/netguides/strategies.html

23. Jornal O Globo; http://www.oglobo.com.br

24. NetSci: http://edisto.awod.com/netsci/index.html

25. Tinker, R. F. J. Sci. Educ.Technol. 1997, 6, 111.

26. Eddy, J. P.; Spaulding, D. Educ. 1996, 116, 391.

27. a) Castro, M.A.S., "Pesquisa Científica e os Novos Ambientes Eletrônicos", Mesa Redonda 48a Reunião Anual da SBPC 1996, http://www.intermidia.icmsc.sc.usp.br/ $\sim$ masc/SBPC.html;

b) de Backer, W.; "Conferência proferida no $39^{\text {th }}$ Internet Engineering Task Force Conference; Munique 1997; ftp:/ /ftp.ietf.org/97aug/debacker-39ieft.txt

28. PICS Standard;http://www.w3.org/pub/www/pics

29. NetShepherd; http://www.netshepherd.com

30. Jacobson, S.; Electronic Learning 1977, 16, 6Y.

31. Friedman, E. A.; Baron, J. D.; Addison, C. J. J. Technol. Horizon Educ. 1996, 23, 83.

32. MacKnight, C. B. J. Comput. Higher Educ. 1996, 8, 144.

33. Global Schoolnet Foundation; http://www.gsn.org/project/ index.html

34. International Education and Resources, http://www.igc.apc. org/iearn

35. Teacher web site http://www.ed.gov/inits/teachers/teach.html

36. NASA; http://quest.arc.nasa.gov/school97

37. Burgsthaler, S. J. Technol. Horizon Educ. 1996, 24, 61.

38. Otsuka, J. L.; 1997; http://penta.ufrgs.br/pesquisa/joice-ti.hmt

39. Biblioteca Virtual UCLA, http://www.chem.ucla.edu/ chempointers.hmtl

40. Biblioteca virtual, http://www.ch.ic.ac.uk/rzepa/cbi

41. Internet Public Library, http://www.ipl.org

42. Thomas, P. Computing \& Control Eng. J. 1997, 8, 136.

43. Weaver, S. New Direction for Adult and Continuing Education 1995, 67, 71.

44. Ellsworth, J. H.; "Education on the Internet: A Hands-on Book of Ideas, resources, Projects, and Advice"; Sams Publising, Indianapolis, USA 1994.

45. Powers, S. M. Comtemporary Educ. 1997, 68, 194.

46. Waddick, J. Educat. Training Technol. Int. 1994, 31, 98.

47. Shuterman, G. P.; Shuterman A. J. J. Chem Ed. 1997, 74, 
771. Este trabalho pode ser obtido no endereço: http:// www.reed.edu/ alan

48. W.J. Treadway, J. Chem Ed. 1996, 73, 876.

49. Ranck, J. P.; "Applications of Technology in Teaching Chemistry: An On-Line Computer Conference", 1993, http://www.inform.umd.edu/EdRes/Topic/Chemistry/ ChemConference

50. Smith, S.; Stowall, I. J. Chem. Ed. 1996, 73, 911.

51. Holmes, J. L.; Gettys, N. C. J. Chem. Ed. 1997, 74, 191. http://jchemed.chem.wisc.edu

52. Chemistry Software and Information Resources; http:// www.csir.org

53. Netlib, http://www.netlib.org

54. Catalog of Public Domain Chemistry Sofware, http:// www.inform.umd.edu/UMS+State/UMD-Projects/MCTP/ Technology/Chemistry.html\#Chemistry Software

55. Chemland; http://soulcatcher.chem.umass.edu/newdocs/cl.html

56. RasMol; http://www.umass.edu/microbio/rasmol

57. ChemConf, 1996, http://www.inform.umd.edu/EdRes/Topic/ Chemistry/ChemConference/ChemConf96/Home.html

58. ChemConf, 1997, http://www.inform.umd.edu/EdRes/Topic/ Chemistry/ChemConference/ChemConf97

59. ChemConf, 1998 http://www.inform.umd.edu/EdRes/Topic/ Chemistry/ChemConference/ChemConf98

60. Conferência Eletrônica em Química de Heterociclos, 1996, http://www.ch.ic.ac.uk/ectoc/echet96

61. Conferência Eletrônica em Organometálicos, 1997, http:/ /www.ch.ic.ac.uk

62. First International Electronic Conference on Synthetic Organic Chemistry, 1997, http://mdpi.org/ecsoc-1.htm\#top

63. Interactive Chemical Application, http://www.nie.ac.sg:8000/ $\sim$ wwwchem/l-teach.html

64. Usenet News in Chemistry, http://www.news:sci.chem

65. Journal of Molecular Modeling http:// science.springer.de/, Chemistry \& Industry Magazine, http://ci.mond.org/; Chemical Engeneering Magazine, http://www.che.com

66. Rzepa, H. S.; Whitaker, B. J.; Winter, M. J.; "Chemistry and the WWW"; 1997, http:// www.ch.ac.ic.uk/rzepa/cbi

67. Tissue, B. M.; "New Initiatives in Chemical Education: Development and Delivery of Chemical-Education Hypermedia Using the World-Wide Web", An On-Line Symposium, Jul. 19, 1996, http://www.chem.vt.edu/ archive/chemconf96/paper04all.html

68. Wiggins, G.; "Use of the Internet in Teaching Chemical Information Courses", 1996, http://www.indiana.edu/ $\sim$ cheminfo/gw/onlinsymp.html

69. Bernholdt, D. E.; Fox, G. Trends Anal. Chem. 1997, 16 , 230. Artigos da coluna Internet publicados no Trends in Analytical Chemistry podem ser obtidos no endereço: http://www.elsevier.com/inca/homepage/saa/trac/ frames.shmtl

70. Hellen, S. R. Trends Anal. Chem. 1997, 16, 174.

71. Van Bakel, B.; Postma, G. Trends Anal. Chem. 1997, 16,63 .

72. Long, G. R.; Zielinski, T. J. Trends Anal. Chem. 1996, $15,445$.

73. Zielinski, T. J.; Shibata, M. Trends Anal. Chem. 1996, $15,429$.

74. AskNPAC, http://www.csir.org

75. Diretório Liszt, http://www.liszt.com

76. ChemFind, http://chemfind.camsoft.com

77. Fact; http://fact.jst.go.jp/fdb/ms

78. QPAT.US, http://www.elsevier.com/inca/homepage/saa/ trac/frames.shmtl
79. Patent-Server-IBM; http://patent.womplex.ibm.com 80. Beilstein NetFire; http://www.beilstein.com/search.hmtl

81. NIST Chemistry WebBook; http://webbook.nist.gov/ chemistry

82. Heller, S. R. Trends Anal. Chem. 1997, 16, 425.

83. ChemDex, http://www.shef.ac.uk/ chem/chemdex

84. WebElements; http://www.shef.ac.uk/chemistry/webelements

85. Chemist's Art Gallery; http://www.csc.fi/lul/chem/ graphics.html

86. Educational Materials for Organic Chemistry, http:// slater.cem.msu.edu/ parrill

87. Chemistry Resources in the Internet; http:// www.inform.umd. edu/UMS+State/UMD-Projects/MCTP Technology Chemistry.html

89. ChemCal; http://www.sfu.ca/chemed

89. WWW no Ensino de Química Inorgânica; http://www.furg. br/furg/deptos/quimica/wwwqgi.html

90. Simulations, http://www.brunel.ac.uk/depts/chem/ch241s/ re_view/addreact.htm

91. Chemistry Web Internet Resources, http://www.nie.ac. sg:8000/ wwwchem/con-chem.html

92. Experimental Chemistry, http://ull.chemistry.uakron.edu/ organic_lab/

93. InfoChem, http://www.infochem.co.uk/index.htm

94. Conference Listing;http://hackberry.chem.niu.edu/Conferences.html

95. Laboratório Aberto IQ-USP; http://www.usp.br/index.html

96. SBQ, A Química na Internet, http://www.sbq.org.br/ chempointers.html

97. ChemTeam; http://maple.lemoyne.edu/ giunta/papers.html

98. Chaves das Neves, H. J., 1997, http://www.dq.fct.unl.pt/ qof/stereo1.html

99. Othmer Library; http://www.chemheritage.org

100. Nobel Prize Archive in Chemistry, http://www.almaz.com/ nobel/chemistry

101. Institute for Learning Technologies, http://www.ilt. columbia.edu

102. Chemistry Teaching Resourses, http://www.anachem.umu.se/ eks/pointers.htm

103. Educational Materials for Organic Chemistry, http:// slater.cem.msu.edu/ parrill/index.html

104. Toreki, R., "The Organometallic Hypertext Book"; 199, http://www.chem.uky.edu/courses/che614/HyperTextBook

105. Amaral, P., "Introdução à Quimiometria" 1997, http:// www.dq.fct.unl.pt/qof/chemomtr.html

106. Rzepa, H. S., "Practice Problems in Pericyclic Reactions", 1997, http://www.ch.ic.ac.uk/GIC/pericyclic

107. Kazakevich, Y.; McNair, H. M., "Basic Liquid Chromatography"; 1997, http://128.173.180.166/my_home/book/ content.html

108. Stoffer, J. O., "Polymer Chemistry Hypertex, 1996, http:/ /www.umr.edu/ wlf

109. Cheah, H.-M. Lasie 1997, 28, 33.

110. ChemWeb ${ }^{\mathrm{tm}}$, http://chemweb.com

111. Chemistry Place, http://www.elsevier.com/inca/homepage/ saa/trac/frames.shtml

112. BioMedNet; http://biomednet.com

113. Ash, J. E.; Boyett, R. E.; Town, W. G. "ChemWeb - The World Wide Club for the Chemical Community" 1997, http://www.elsevier.com/inca/homepage/saa/trac/ frames.shtml

114. Lima Junior, A. W.; "As perspectivas da Internet no Brasil"; Ciência do Leitor, O Globo 1997, http:// www.oglobo.com.br 